\title{
ISB News July 2008
}

Dear Fellow ISB Member:

I couple of final announcements for this edition of the ISB News. First, a final reminder about the upcoming International Congress of Biometeorology, which will take place in Tokyo, Japan from September 22-26. The Congress theme is Harmony within Nature, and Dr. Iriki and the organizing committee have combined a very interesting array of scientific talks with a very good social program. I hope to see any many of you there as I can (see http://www.icb2008. $\mathrm{com} /$ for details). The second final reminder is regarding the upcoming Biometeorology Bulletin. For this edition,
I am looking to highlight individual research, so if you have been doing interesting or exciting research, please send me an email, and I will try to include as many items in the Bulletin as I can. Of course, please also see biometeorology.org for information about the Society, and also feel free to contact me with any thoughts or suggestions on how to improve the ISB.

Scott Greene

ISB Secretary

e-mail: jgreene@ou.edu 